\title{
Does adaptation to climate change and variability provide household food security? Evidence from Muger sub-basin of the upper Blue-Nile, Ethiopia
}

\author{
Abayineh Amare* and Belay Simane
}

\begin{abstract}
Introduction: The purpose of this study is to evaluate the associated impact of adoption of adaptation options to climate change and variability on household food security in the Muger sub-basin of the upper Blue-Nile of Ethiopia using a comprehensive data of 442 sampled households from four representative districts' in the sub-basin. The study used a propensity score matching approach to evaluate the impact of adaptation options on household food security.

Results: Results show that the decision to adopt adaptation options is found to be positively influenced by male household heads, family size, access to extension service, the size of landholding, and frequency of drought and floods over the past many years. The results further reveal that farmers adopting any of the adaptation options had higher food calorie intake per day per adult equivalent than those who did not.

Conclusions: A policy that promotes the adoption of soil and water conservation measures, small-scale irrigation, agronomic practices, and livelihood diversification strategies should be central to food security strategy in the study area.
\end{abstract}

Keywords: Food security, Impact, Adaptation, Climate change, Muger sub-basin

\section{Introduction}

The impact of climate change on food security in SubSaharan Africa have largely been explored by a plethora of authors using either agronomic model or Ricardian analysis (Thornton and Herrero 2014; Beddington et al. 2012; Thornton et al. 2012; Conway 2011; Deressa and Hassan 2010). Empirical literature shows that Ethiopia is the most vulnerable country owing to its least adaptive capacity and low diversified economies (Stige et al. 2006). This becomes even more complicated where Ethiopia's agricultural systems have largely relied on rain-fed that has been closely associated with climate (World Bank 2006). It has been noted that extreme climate events such as drought and floods reduced one third of Ethiopia's economic growth (World Bank 2006).

\footnotetext{
* Correspondence: abaytana82@gmail.com; abayineh.amare@aau.edu.et College of Development Studies, Addis Ababa University, Addis Ababa, Ethiopia
}

A large body of literature has recognized adaptation as one of the policy options in response to climate change impact (Smit et al. 1999; Smith and Lenhart 1996; UNFCCC 1992). It is seen as critical to a great extent to reduce the ultimate effect of climate change on agriculture so as to improve livelihoods and food security of rural households in the continent (van de Giesen et al. 2010; Vermeulen et al. 2012). "Adaptation to climate change refers to adjustment in natural or human systems in response to actual or expected climatic stimuli or their effects, which moderates harm or exploits beneficial opportunities" (FAO 2011; IPCC 2011).

Given serious problem posed by climate change, many potential adaptation options have been suggested for developing countries. For instance, soil and water conservation (SWC) practices have been suggested in response to soil erosion problem posed by climate (Amare and Simane 2017a, 2017b; McCarthy et al. 2011; 
Amsalu and De Graaff 2007). Based on the data from a comprehensive survey of agricultural households across three agro-ecologies in Muger River sub-basin of the Blue-Nile Basin, Amare and Simane (2017b) identified soil and water conservation practices are most widely used adaptation option in response to climate change. The use of these adaptation options was found to reduce soil erosion associated with short but heavy rains. Farmers are adapting SWC practices to retain soil-water content and maintain humidity during dry spells through an improved soil structure (McCarthy et al. 2011). Similarly, the use of different agronomic practices is considered as the potential adaptation option to the adverse effects of climate change on agriculture. The analysis by Amare and Simane (2017b) in the Muger River sub-basin showed that using agronomic practices such as droughttolerant crop varieties, crop diversification, and improved crop varieties is an another dominant strategy that is found to be used by smallholder farmers in adapting to the negative effects of climate variability and change as well as resultant changes in crop pest and disease pressures. Improved varieties (drought-tolerant varieties and/ or short cycle) allow for increased productivity even during dry seasons (Lobell et al. 2008). Furthermore, Ellis and Freeman (2004) found that crop diversity is used as a strategy for risk avoidance due to sharp fluctuations in crop yield or prices.

It is also disclosed that because of the unreliable and erratic pattern of rainfall and repeated drought, farmers in the study area started using small-scale irrigation schemes on their farm. It is also observed that diverted streams, pond construction, and use of water pump are found to be the major means for small-scale irrigation in the study area (Amare and Simane 2017b). In response to the adverse effects caused by climate variability and change, smallholder farmers have been diversifying their sources of livelihood with an understanding of more diversified livelihood strategies lead them both to enhance incomes and spread the risk for smallholder farmers. This includes the use of on-farm, off-farm, and non-farm activities (Amare and Simane 2017b; Morton 2007). However, despite large investment in adaptation options in response to the adverse effect of recurrent drought and floods, households in the study area continue to suffer from food insecurity.

Studies have been undertaken to measure the impact of climate change on Ethiopia agriculture and explored possible adaptation options in response to its adverse effect (Deressa 2007; Kidane et al. 2006; NMSA 2001). Insights from these studies are crucial in appreciating the extent of the problem and designing appropriate adaptation options. Notwithstanding the upsurge in the promotion of such adaptation options in recent years, there have been limited empirical studies that attempted to analyze their impacts on household food security (Ali and Erenstein 2017; Asfaw et al. 2015; Gebrehiwot and Anne Van Der 2015). Farmers adopting more adaptation practices had higher food security levels than those who did not (Ali and Erenstein 2017). Similarly, the analysis by Gebrehiwot and Anne Van Der (2015) using food security package program that has been implemented in Tigray regional state as an adaptation option to changing climate showed that the program has had a significant effect on improving household food calorie intake. Using a survey conducted in Ethiopia, Asfaw et al. (2015) showed that the adoption of climate-smart agricultural practice have positive and significant impacts on the objective measure of food security (net crop income) but no impact is observed for the subjective food security indicator.

However, there is inadequate evidence to what extent that adoption of those adaptation options impacted household food security in Ethiopia in general and in Muger sub-basin in particular. The results of these previous studies are highly fragmented and are of little help in addressing local conditions in relation to adaptations to climate change. Moreover, the studies overlooked the likelihood household food security impact of adaptation options at the household level. Using household-level data collected from a random cross-sectional sample of 442 farmers in the study area, the aim of the current study is to provide a comprehensive analysis on the impact of adaptation options of climate change and variability in the Muger sub-basin of the upper Blue-Nile of Ethiopia. The specific objective of the paper is, therefore, to estimate the effect of adoption of soil and water conservation measures, small-scale irrigation, agronomic practices, and livelihood diversification strategies as climate change adaptation options on household food security status measured by household calorie intake/day per adult equivalent using propensity score matching techniques. Addressing this question provides empirical evidence on the importance of adaptation options in improving household food security. Furthermore, this study provides important insights and lessons on the importance of access to resources on the ability of the farm households to invest in climate change adaptation options that latter improve household's capacity to adopt adaptation options to changing the climate. In addition, the finding of the study can be used in designing better adaptation interventions that can accommodate the existing resource potentials.

\section{Description of the study area Bio-physical setting}

Muger sub-basin is part of the upper Blue-Nile basin and cover a total area of $8188 \mathrm{~km}^{2}$. Muger River flows from the southeast of the basin into Abbay River. The altitude in Muger sub-basin ranges between 953 and 3550 masl. 
The highlands in the eastern and southern part of the sub-basin are higher in altitude, greater than $2600 \mathrm{~m}$ up to $3550 \mathrm{~m}$. The lowlands along the Muger River have lower altitude less than 1700 masl (Denekew and Seleshi 2009).

Following Deressa et al. (2009) classification of agroecological zones of Ethiopia, Kolla agroecology (lowland) is characterized by relatively hotter and drier climate, whereas Weyina Dega (middle land) and Dega agroecology (Highland) are wetter and cooler. Using this classification, the sub-basin of the study area contains Kolla, Woyina Dega, and Dega agro-ecological zones (Fig. 1). Evidence revealed that farmers living in different agroecological settings have their own choice of adaptation methods (Deressa et al. 2009; Legesse et al. 2013; Tessema et al. 2013). Moreover, farmer's vulnerability to climate change varies among different agro-ecological zones because there exists spatial heterogeneity among agro-ecological zones in terms of a varying level of socioeconomic and infrastructure development, households access to resources, level of food insecurity, and the ability to cope (Amare and Simane 2017c). Diversity in topography, socio-economic, and environmental issues determine the types of adaptation options farmers used in response to climate change.

The sub-basin has an annual rainfall that varies between 833 and $1326 \mathrm{~mm}$. Lower annual rainfall ranging from $833 \mathrm{~mm}$ up to $1000 \mathrm{~mm}$ is observed along the river and lowlands. Relatively high rainfall is found in the highlands of the sub-basin. The annual maximum and minimum temperature of the sub-basin varies between $16-31.5{ }^{\circ} \mathrm{C}$ and $3-16.5{ }^{\circ} \mathrm{C}$, respectively. Temperature is higher along the river with a maximum of $28-31.5{ }^{\circ} \mathrm{C}$ and minimum of 13-16.5 ${ }^{\circ} \mathrm{C}$. The sub-basin is characterized by tepid to cool moist highlands. The northwestern part of the lowlands is hot to warm moist lowlands (Denekew and Seleshi 2009).

Besides the biophysical characteristics of the sub-basin, Figs. 2 and 3 present the trend in the annual maximum and minimum temperature data from the year 1990 to

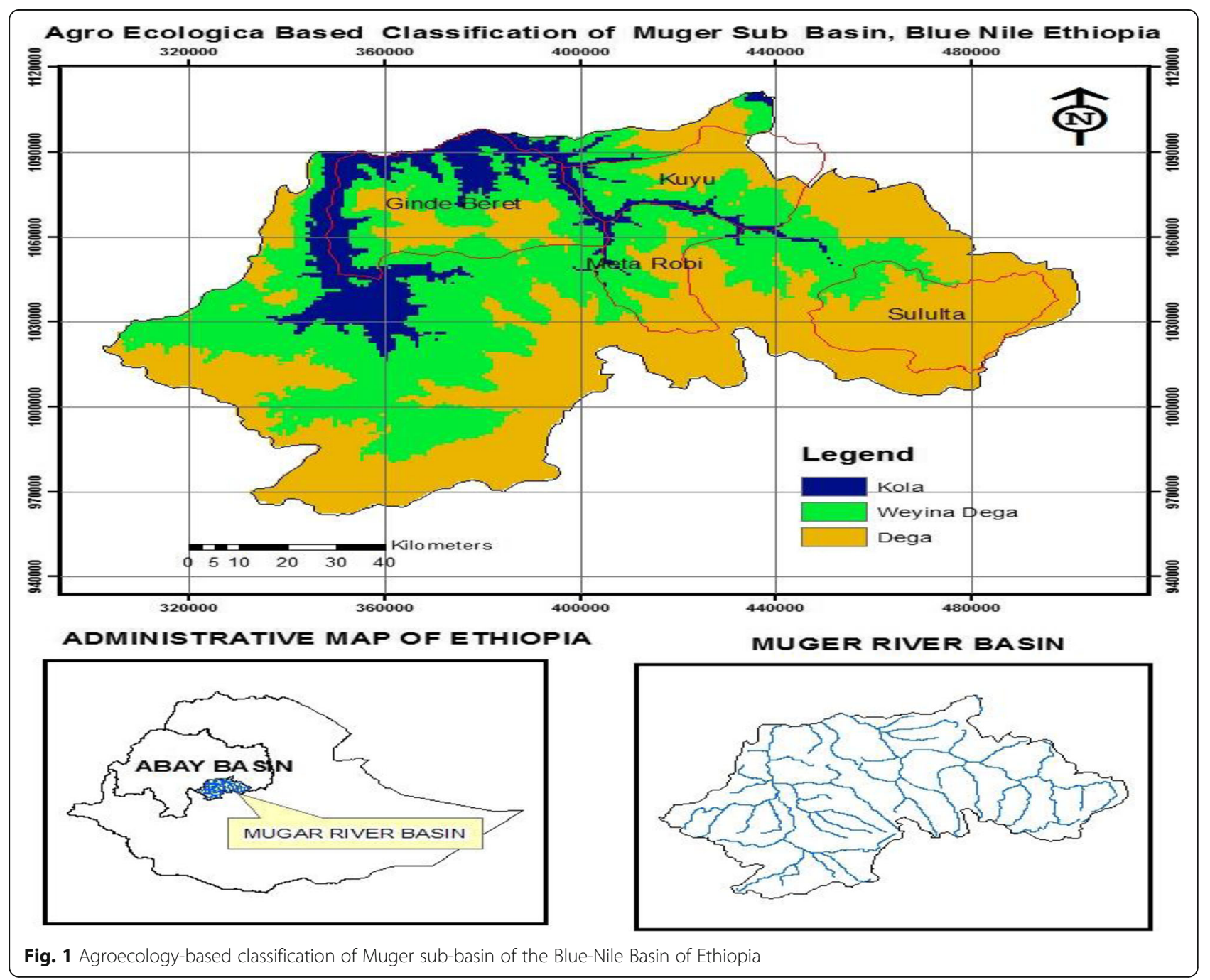




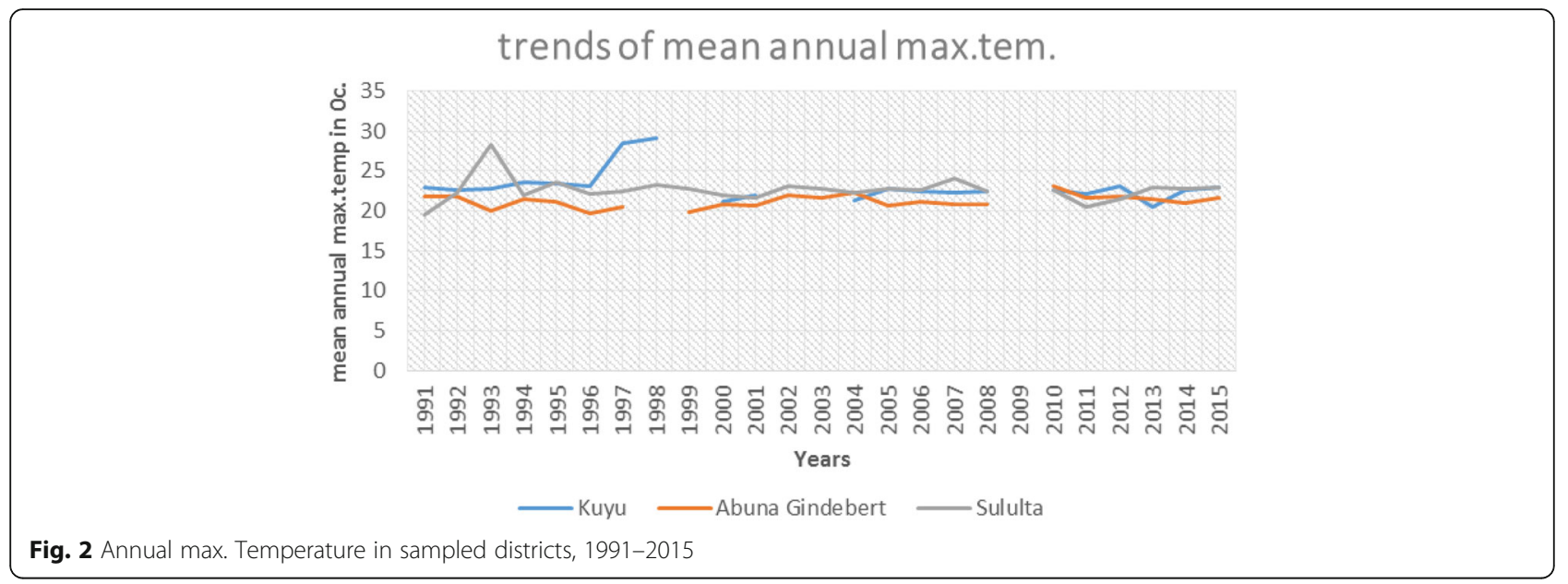

2015 for the three metrology stations found in the sampled districts namely Gebereguracha station for the Kuyu district, Sululta station for the Sululta district, and Kachisi station for Abuna Gindeberet district, respectively. Similarly, Fig. 4 illustrates the trend in the annual precipitation in the selected stations. The mean annual temperature and rainfall records over the period under consideration were computed from the daily temperature and rainfall records obtained from each metrology station. The rainfall trend suggests a fluctuating and general decline in rainfall values over the study area. The results show a noticeable decline is observed in Sululta district in rainfall values from 1991 to 1992 and from 2006 to 2007. The result further shows that a noticeable decline in rainfall is observed from 1997 to 1998 in Kuyu district. It is this variability that created a decline in crop production and productivity and/or a total crop failure due to insufficient rainfall during the production seasons in the study area. This problem is more prevalent in Abuna Gindeberet district where most of the area of the district fall under kolla agro-ecological zone. Although the mean of maximum temperature at Abuna Gindebert and Sululta districts is more or less constant over years, an increasing trend is observed at Kuyu district between the years 1996 and 2000.

The major soils of the sub-basin are Leptosols, Luvisols, Vertisols, Fluvisols, and Alisols. Leptosols represents the most widely occurring soils within the sub-basin. The second dominant soil is Luvisols. Small patches of Cambisols, Nitosols, and Rigosols are also found in some parts of the sub-basin.

\section{Socio-economic setting}

According to the current zonal structure, the sub-basin is shared between three zones: North shoa, West Shoa, and Oromia regional state Finfine special zone. Muger sub-basin covers 15 weredas: Ejersa (Addis Alem), Walmara, Juldu, Mulo, Sululta, Adda Berga, Meta Robi, Yaya Gulelena Debre Libanos, Wichalena Jido, Ginde Beret, Kuyu, Kutaya, Gerar Jarso, Degem, and Wara Jarso. The total population of the sub-basin is 2,442,247 people (Denekew and Seleshi 2009).

The Muger sub-basin is predominantly rural in character, and the farmers are engaged in small-scale and subsistence mixed agriculture. The dominant sources of livelihoods in the sub-basin are land and livestock.

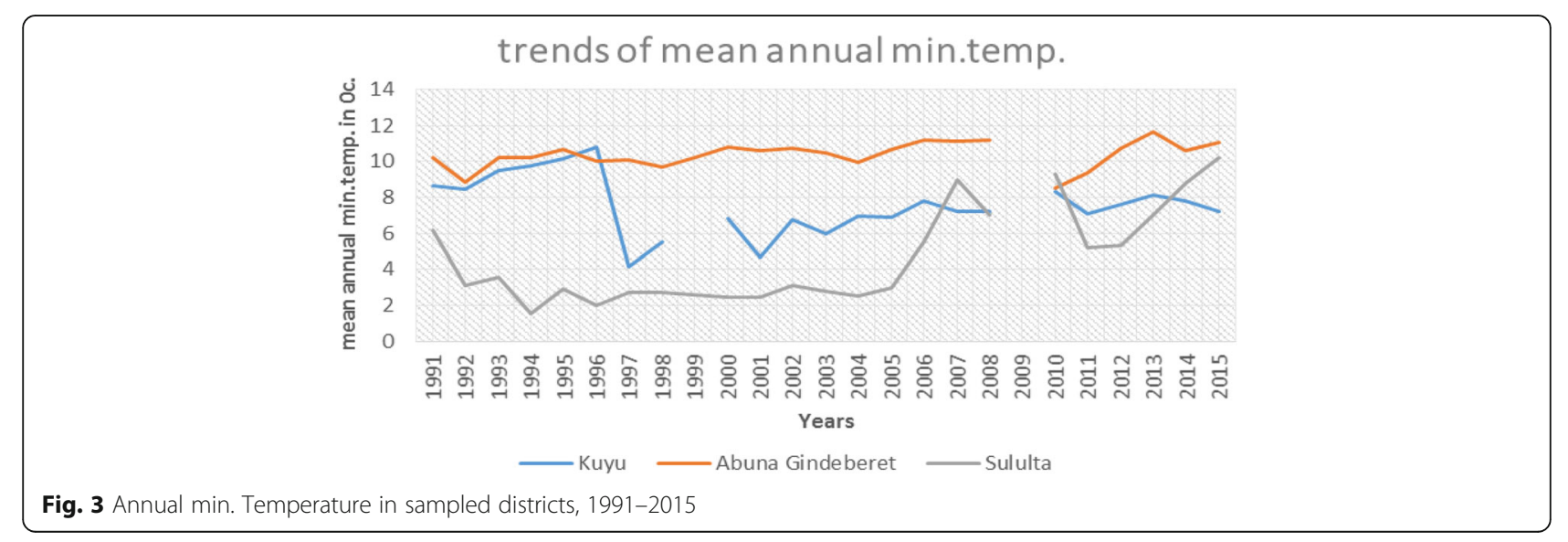




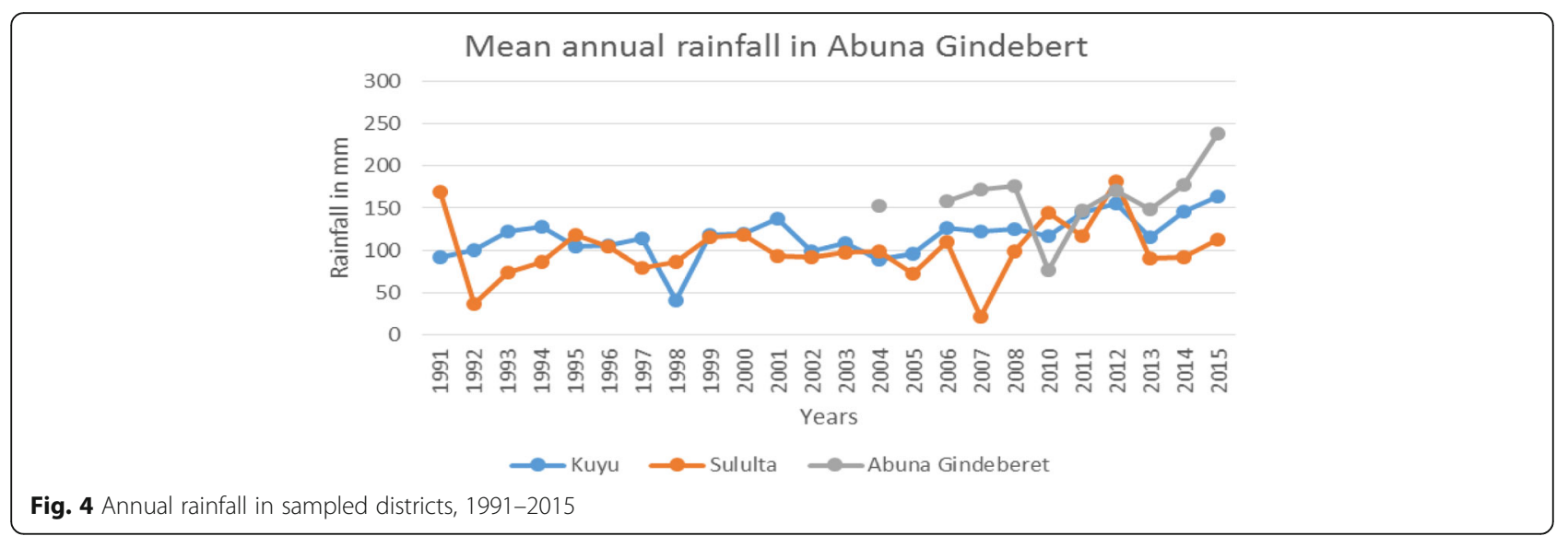

Muger sub-basin falls under three major livelihood zones including (1) Abay-Muger-Jemma Sorghum and Teff Belt Livelihood Zone where its category of food economy is mixed farming and its basic economic activities lie on crop and livestock production; (2) Ambo Selale Ginde-Beret Teff and Wheat Livelihood Zone which have mixed farming system and the main economic activities are a crop, livestock, and livestock product production; (3) Selale-Ambo Highland Barley, Wheat and Horse bean Belt Livelihood Zone with an economy characterized by the cultivation of rain-fed cereals complemented by livestock rearing and sales of trees and fodder (Denekew and Seleshi 2009).

\section{Methods}

\section{Sampling procedure}

The research design was based on multi-stage sampling procedure. In the first stage, the whole sub-basin constituting 15 Districts were grouped into three strata (Kolla, Woyina Dega, and Dega agro-ecological zones) based on their agro-ecological characteristics including the rainfall, soil, and topography. Then, Abuna Gindeberet district and Sululta district were randomly selected from Kola and Dega agro-ecological zones respectively. Similarly, two districts, namely Meta Robi and Kuyu Districts were also selected from Woyina Dega agro-ecology using simple random sampling technique. In the second stage, only PAs found in the sub-basin in each sampled District were listed in consultation with agricultural experts in the area. This is mainly to exclude PAs which are not part of the sub-basin in that particular District. Then, four PAs were randomly selected from each selected district. The third stage was a random selection of 450 respondents from the sampling frame of all the selected PAs using random sampling technique on the basis of probability proportional to size (PPS). The sampling frame was the list of households which was obtained from the PAs administration. Households for Focused Group Discussions (FGD) were also drawn from each identified district, and a member of the group was identified with the help of development agents working in the area.

\section{Types of data and methods of data collection}

Focused Group Discussions (FGD) and household survey were used to collect qualitative and quantitative data, respectively. Data from the FGDs' were used to complement the information obtained through a household survey in order to have a better understanding of causes of food insecurity and the causal influence of different adaptation options on food security. There were eight focus-group discussions held in three agroecology of which four were in Woyina Dega and two in each of the other two agroecology. The focus groups were composed of six to eight elders. One focus group in each of agroecology was composed of women who were perceived to have a deep knowledge of food security challenges and impacts of climate change on food security.

Quantitative data were collected using household survey comprised the same sets of questions. The dataset consisted of food security variables (total grain produced, total grain purchased, total grain obtained through FFW, total relief food received, total crop used for seed, total marketed output); adaptation options (SWC, small-scale irrigation, agronomic practices, livelihood diversification strategies); asset ownership (landholding, livestock ownership); social capital (local institutions/organizations households are membership); and human capital and access to financial capital. The survey also covered data on several factors including households' demographic and socioeconomic characteristics (age, education, gender, and family size) as well as environmental variables such as access to the early warning system, the frequency of occurrence of drought, and their experience's in crop failure due to climate change and variability.

\section{Treatment variable}

The treatment variable is based on the question "what adaptation options are households used to ameliorate 
the adverse impact of climate change and variability"? The results from our analysis showed that soil and water conservation measures, small-scale irrigation, agronomic practices, and livelihood diversification are found to be the dominant adaptation options that farmers used in response to climate change and variability.

\section{Outcome variable}

The outcome variable that we used in this analysis is household food security status measured in household food calorie intake/day per adult equivalent. We used a household food balance model to compute the status of household food security using total grain produced by household; total grain purchased by household; total grain obtained through Food for Work (FFW) by household; total relief food received by household; postharvest losses to household; total crop utilized for seed from the home by the household; and total marketed output by household in a year of the survey period. The method is originally developed by FAO (1996) and later modified and used by many authors to measure food security status of households (Mesay 2010; Eshetu 2000; Degefa 1996).

\section{Methods of data analysis \\ Impact estimation strategies}

If the adaptation options were randomly assigned to farmers, we could assess the impact of their adoption on households' food security by comparing the average consumption of adapters and non-adapters. In such a case, the average treatment effect (ATE) can be computed as follows:

$$
\mathrm{ATE}=E(Y 1 \mid D=1)-E(Y 0 \mid D=1)
$$

This is based on the assumption that the output levels of the adapters before their adoption $(E(Y 0 \mid D=1)$ can reasonably be approximated by the output level of nonadapters during data collection $(E(Y 0 \mid D=0)$. Otherwise, estimation of ATE using the above equation is not possible since we do not observe $E(Y 0 \mid D=1)$ though we do observe $E(Y 1 \mid D=1)$ and $(E(Y 0 \mid D=0)$. However, adaptation options are rarely randomly assigned. Instead, adoption usually occurs through self-selection of farmers or, sometimes, through program placement. In the presence of self-selection or program placement, the above procedure may result in a biased estimation of the impacts of adaptation options since the treated group (i.e., the adapters) are less likely to be statistically equivalent to the comparison group (i.e., the non-adapters) in a nonrandomized setting.

The literature shows various methods to address this selection bias. Some studies have adopted the Heckman two-step method that assumes a normal distribution of unobserved variables. Another method employs instrumental variables (IV). This approach usually requires at least one variable in the treatment equation to serve as an instrument for the specification of the outcome equation. Moreover, both ordinary least square (OLS) and IV procedures restrict the model to take a linear functional form, implying that the coefficients on the control variables are similar for treatment and control groups (Ali and Abdulai 2010).

In the absence of experimental data, the PSM is a widely used method to account for this sample selection bias, which is also employed in this study. The PSM technique pairs the treatment (adapters) and control (non-adapters) groups based on the similarity of observable characteristics (Ali and Abdulai 2010). Unlike the OLS and IV techniques, the PSM technique relaxes the assumptions of functional form, normal distribution of unobserved covariates and finding instrumental variables for the specification of the outcome equation. It only requires a set of observable covariates for matching and to determine causal effects of treatment on the outcome variable (Heckman and Vytlacil 2007). One limitation of PSM is that it does not account for the unobservable variables directly; rather, it assumes that selection is based on observable variables. PSM can be a better choice when instruments are weak or not available (Ali and Abdulai 2010). PSM is defined as the conditional probability that a farmer adapts to climate change, given the pre-adaptation characteristics (Rosenbaum and Rubin 1983).

In order to measure the impact of adaptation options (soil and water conservation, agronomic practices, livelihood diversification, and small-scale irrigation) in response to climate change and variability, this research used Propensity score matching technique. The first step in estimating the treatment effect is to estimate the propensity score. To get this propensity scores, any standard probability model can be used (for example, logit, probit or multinomial logit) (Rajeev et al. 2007). Since the propensity to adoption is unknown, the first task in matching is to estimate this propensity. Any resulting estimates of program effect rest on the quality of the adoption estimate. This can be routinely carried out using a choice model. Which choice model is appropriate depends on the nature of the program being evaluated. If the program offers a single treatment, the propensity score can be estimated in a standard way using, for example, a probit or logit model, where the dependent variable is "adaptation" and the independent variables are the factors thought to influence adaptation and outcome (Getachew et al. 2011b).

After obtaining the predicted probability values conditional on the observable covariates (the propensity scores) from the binary estimation, matching was done 
using a matching algorithm that was selected based on the data at hand. Then, the effect of household's adaptation in response to climate change on a given outcome (outcome in this study is food security measured in food calorie intake) $(Y)$ is specified as:

$$
\tau_{i}=Y_{i}\left(D_{i}=1\right)-Y_{i}\left(D_{i}=0\right)
$$

where $\tau_{i}$ is treatment effect (effect due to adaptation), $Y_{i}$ is the outcome on household $i$, and $D_{i}$ is whether household $i$ has got the treatment or not (i.e., whether a household adapted to climate change or not).

However, one should note that $Y_{i}\left(D_{i}=1\right)$ and $Y_{i}\left(D_{\mathrm{i}}=0\right)$ cannot be observed for the same household at the same time. Depending on the position of the household in the treatment (adoption of adaptation options), either $Y_{i}\left(D_{i}\right.$ $=1$ ) or $Y_{i}\left(D_{i}=0\right)$ is the unobserved outcome (called counterfactual outcome). Due to this fact, estimating individual treatment effect $\tau_{I}$ is not possible and one has to shift to estimate the average treatment effects of the population than the individual one. Most commonly used average treatment effect estimation is the average treatment effect on the treated $\left(\tau_{\mathrm{ATT}}\right)$ and specified as:

$$
\begin{aligned}
\tau_{\mathrm{ATT}} & =E(\tau / D=1) \\
& =E[Y(1) / D=1]-E[Y(0) / D=1]
\end{aligned}
$$

As the counterfactual mean for those being treated, $E[Y(0) / D=1]$ is not observed, one has to choose a proper substitute for it in order to estimate the average treatment effect (ATT). One may think to use the mean outcome of the untreated individuals, $E[Y(0) / D=0]$ as a substitute to the counterfactual mean for those being treated, $E[Y(0) / D$ $=1$ ]. However, this is not a good idea, especially in nonexperimental studies, because it is most likely that components which determine the treatment decision also determine the outcome variable of interest.

In this particular case, variables that determine household's decision to adopt could also affect household's food security. Therefore, the outcomes of individuals from treatment and comparison group would differ even in the absence of treatment leading to a self-selection (Dehinenet et al. 2014; Getachew et al. 2011a). Subtracting $E[Y(0) / D=0]$ from Eq. 3 yields the following specification for ATT:

$$
\begin{aligned}
\mathrm{E}[\mathrm{Y}(1) / \mathrm{D} & =1]-\mathrm{E}[Y(0) / D=0] \\
& =\tau_{\mathrm{ATT}}+E[Y(0) / D=1]-E[Y(0) / D=0]
\end{aligned}
$$

Both terms in the left hand side are observables and ATT can be identified, if and only if $E[Y(0) / D=1]-$ $E[Y(0) / D=0]=0$, i.e., when there is no self-selection bias. This condition can be ensured only in social experiments where treatments are assigned to units randomly (i.e., when there is no self-selection bias). In non-experimental studies, one has to introduce some identifying assumptions to solve the selection problem.

The validity of the outputs of the PSM method depends on the satisfaction of two basic assumptions, namely, the Conditional Independence Assumption (CIA) and the Common Support Condition (CSC) (Becker and Ichino 2002). CIA (also known as Confoundedness Assumption) states given a set of observable covariates $(\mathrm{X})$ which are not affected by treatment (in our case, adaptation), potential outcomes (food security measured by food calorie intake) are independent of treatment assignment (independent of how adaptation decision is made by the household). This assumption implies that the selection is solely based on observable characteristics, and variables that influence treatment assignment (adaptation decision is made by the household) and potential outcomes (food security) are simultaneously observed (Getachew et al. 2011b). The common support condition entails the existence of sufficient overlap in the characteristics of the treated and untreated units to find adequate matches (or a common support).

Three commonly used matching algorithms, namely nearest neighbor matching, radius matching, and kernelbased matching, were employed to assess the impact of adaptation options (soil and water conservation, water harvesting, and small-scale irrigation) on households' food security. The nearest neighbor matching (NNM) method matches each farmer from the adopter group with the farmer from the non-adopter group having the closest propensity score. The matching can be done with or without replacement of observations. NNM faces the risk of bad matches if the closest neighbor is far away. This risk can be reduced by using a radius matching (RM) method, which imposes a maximum tolerance of the difference in propensity scores. However, some treated units may not be matched if the dimension of the neighborhood (i.e., the radius) is too small to contain control units. The kernel-based matching (KM) method uses a weighted average of all farmers in the adopter group to construct a counterfactual. The major advantage of the KM method is that it produces ATT estimates with lower variance since it utilizes greater information; its limitation is that some of the observations used may be poor matches.

\section{Results and discussions} Adaptation options

The study explored four dominant adaptation options used by smallholder farmers in response to the adverse effects of climate change and variability in the study area. These include soil and water conservation (28.7\%); small-scale irrigation (27.4\%); livelihood diversification (14\%); and agronomic practices $(11.5 \%)$. The rest $18.8 \%$ of households are 
found to be non-adopter of the adaptation options. To evaluate the total impact of these adaptation options on household food security calorie intake, we created a new data set by driving a binary variable equal to 1 if households adopted either of the adaptation options and 0 if households did not adopt any of the adaptation options. Based on this categorization, we found that 81 . $2 \%$ of the households are falling under adopter group, and the $18.8 \%$ of the households are non-adopter.

\section{Comparison of adopters and non-adopters of adaptation options}

Tables 1 and 2 present the $t$ test and chi-square comparison of means of selected variables between adopters' categories for adaptation options, respectively. Results show that positive and significant difference is observed in the age of household head, family size, social capital, land holding, distance to the nearest market, livestock holding, and a number of drought events for adopters of adaptation options. Moreover, adopters of adaptation options are also distinct in terms of agroecology, the gender of the household head, access to training, and access to credit.

The results also reveal that the adopter group is also significantly distinguishable in terms of food security status, measured in terms of household food calorie intake/day per adult equivalent. As far as calorie intake is concerned, adopters of adaptation options tend to have higher calorie intake as compared to the non-adopters. The mean calorie intake/day per adult equivalent is 4508 and $1549 \mathrm{kcal}$ for adopters and non-adopters, respectively (Table 1 ). The $t$ test result also shows that there exists a significant and positive difference between the two adopter groups in their calorie intake/day per adult equivalent.

\section{Determinants of adoption of adaptation options}

Given that variety of differences exist between adopters and non-adopters of adaptation options, it is important to control for these potential underlying effects in order to ensure reliable impact estimates. In order to provide information on household's probability of adopting adaptation options on household food security, a probit model is used to match adopter and non-adopter households. The results of the probit model presented in Table 3 depict estimated parameters on the adoption of climate change adaptation options.

The results from the probit model estimates indicate that gender is positively and significantly related to the adoption of adaptation options at 1\% significance level. The result is in conformity with the previous argument by showing that male-headed households had better opportunity to take an adaptation measure than female household mainly due to cultural and social barriers that limit women's access to land and information climate change (Deressa, Yehualashet, Rajan, 2014; Asfaw and Admassie, 2004). The model result of this study reveals that size of cultivated land significantly increases the likelihood of using adaptation options at 5\% significance level. On average, the probability of using adaptation options increases by $10.7 \%$ as the proportion of farm size increases by $5 \%$. Furthermore, access to extension services has a significant influence on adoption of adaptation options. As expected, the influence of access to extension service on farmer's decision to invest in adaptation is significantly positive $(p<0.000)$. Having access to extension service increases the probability of adoption of adaptation options by $22.8 \%$.

Better access to early warning information about drought and flood before it happened has a significant and positive impact on the likelihood of using different adaptation options at $10 \%$ significance level. The result reveals that getting access to climate warning about drought and/or flood increases the likelihood of using adaptation option by $5.04 \%$. This finding is in line with results of previous studies that showed a positive relationship between early warning information and farmer's decision to adopt adaptation option (Deressa, Yehualashet, Rajan, 2014; Phillipo, Bushesha, Mvena, 2015). On the contrary, livestock holding in TLU

Table 1 Descriptive statistics of continuous variables used in regression

\begin{tabular}{|c|c|c|c|c|c|c|}
\hline \multirow[t]{2}{*}{ Variable } & \multicolumn{2}{|c|}{ Adopters $(N=359)$} & \multicolumn{2}{|c|}{ Non-adopters $(N=83)$} & \multirow[t]{2}{*}{$t$ value } & \multirow[t]{2}{*}{ Sig. } \\
\hline & Mean & SD & Mean & SD & & \\
\hline Age of $\mathrm{HH}$ & 46.09 & 12.392 & 42.72 & 13.544 & 2.076 & 0.040 \\
\hline Education of $\mathrm{HH}$ & 2.58 & 3.470 & 2.33 & 3.212 & .639 & 0.524 \\
\hline Family size & 6.09 & 1.993 & 5.08 & 1.945 & 4.209 & 0.000 \\
\hline Social groups & 2.72 & 1.319 & 2.24 & 1.274 & 3.057 & 0.003 \\
\hline Land ownership & 2.73 & 1.678 & 1.47 & 1.183 & 8.016 & 0.000 \\
\hline Distance to market & 1.59 & 0.858 & 1.88 & .998 & -2.457 & 0.016 \\
\hline Livestock ownership & 6.85 & 4.893 & 4.92 & 4.870 & 3.249 & 0.001 \\
\hline Climate & 4.44 & 3.328 & 3.43 & 2.073 & 3.501 & 0.001 \\
\hline Food security status & 4508 & 3876.90 & 1549 & 648.59 & 13.487 & 0.000 \\
\hline
\end{tabular}


Table 2 Descriptive statistics of categorical variables used in regression

\begin{tabular}{|c|c|c|c|c|c|}
\hline Variable & & Adopters (359) & Non-adopters (83) & Chi-Square & Sig. \\
\hline \multirow[t]{3}{*}{ Agroecology } & Kola & 107 & 36 & 8.734 & 0.013 \\
\hline & Woyina Dega & 163 & 37 & & \\
\hline & Dega & 89 & 10 & & \\
\hline \multirow[t]{2}{*}{ Gender of the $\mathrm{HH}$} & Male & 341 & 34 & 152.980 & 0.000 \\
\hline & Female & 18 & 49 & & \\
\hline \multirow[t]{2}{*}{ Access to extension service } & Yes & 254 & 12 & 89.152 & 0.000 \\
\hline & No & 105 & 71 & & \\
\hline \multirow[t]{2}{*}{ Access to credit } & Yes & 115 & 16 & 5.260 & 0.022 \\
\hline & No & 244 & 67 & & \\
\hline
\end{tabular}

negatively influences household's decision to adopt adaptation options at $5 \%$ probability level. This result reveals that a unit increase in a number of livestock in TLU would result in a $3.35 \%$ decrease in the probability of adopting adaptation options. Finally, the results from the probit model show that farmers decision to adopt adaptation options is not significantly influenced by the variables agroecology, access to credit, distance to the nearest market, social capital, education status, and age of the household head.

\section{Estimation results of propensity scores}

After calculating the propensity scores, the nearest neighbor matching (NNM) method, Kernel Matching, Stratification Matching, and Radius Matching were employed to match the control group of individuals (non-adapters) to the treated group (adapters) based on

Table 3 Estimation of propensity score through probit regression model

\begin{tabular}{lllll}
\hline Adoption & Coef. & Std. Err & z-value & Sig. \\
\hline Agroecology & .31019 & .20626 & 1.50 & 0.133 \\
Gender of HH & 1.9498 & .24496 & 7.96 & 0.000 \\
Age of the HH & -.00252 & .00876 & -0.29 & 0.774 \\
Education & -.03589 & .03203 & -1.12 & 0.263 \\
Family size & .16198 & .05581 & 2.90 & 0.004 \\
Social capital & .14003 & .10045 & 1.39 & 0.163 \\
Total land size & .32195 & .10689 & 3.01 & 0.003 \\
Access to extension service & 1.3541 & .22822 & 5.93 & 0.000 \\
Access to credit & .31800 & .24587 & 1.29 & 0.196 \\
Market distance & -.15333 & .11874 & -1.29 & 0.197 \\
livestock & -.07169 & .03354 & -2.14 & 0.033 \\
Early warning information & .09858 & .05041 & 1.96 & 0.051 \\
_cons & -3.2501 & .69312 & -4.69 & 0.000 \\
\hline
\end{tabular}

Probit regression

Number of observation $=442$

LR $\mathrm{chi}^{2}(12)=231.61$

Prob $>\mathrm{chi}^{2}=0.000$

Pseudo $R^{2}=05425$

Log likelihood $=-97.676355$ similar propensity scores. During the matching process, all the matching methods employed discard the unmatched non-adapters, and hence, they lead to the reduction in sample size for the post-matching impact analysis. The region of common support is [.01697335, .99999403] and the balancing property also satisfied.

The results confirmed there exist a considerable overlap in common support. Figure 5 shows the distribution of propensity scores of matched and unmatched individuals in both groups. The result guarantees a sufficient overlap in the distribution of the propensity score between adopters and non-adopters. The bottom half of the graph stands for the propensity score distribution for the non-adopters and the upper half refers to the adopters. The densities of the scores are on the $y$-axis. In the next step, we calculated the average adaptation effects on the status of household food security (Table 4).

\section{Estimation of the treatment effect}

The correlation between adoption of adaptation options and household food security outcome such as household calorie consumption/day per adult equivalent is theoretically complex and there are further empirical pitfalls regarding the impact evaluation problem. We estimated the calorie consumption effect of climate change adaptation options based on cross-sectional data available. A propensity score matching technique was used to address the research questions.

Table 4 presents the estimated effects of the adaptation options on the household food security by nearest neighbor matching (NNM), Kernel-based matching (KBM), and stratification matching methods. The post-matching result from nearest neighbor matching reveals that adaptation tends to positively and significantly affect household calorie intake. The estimates of nearest neighbor matching show that adoption of adaptation options improves household food calorie intake by $2635 \mathrm{kcal} /$ day per adult equivalent. Similarly, the Kernel matching result reveals adopting either of the adaptation options also guarantee favorable effect on food security. This 


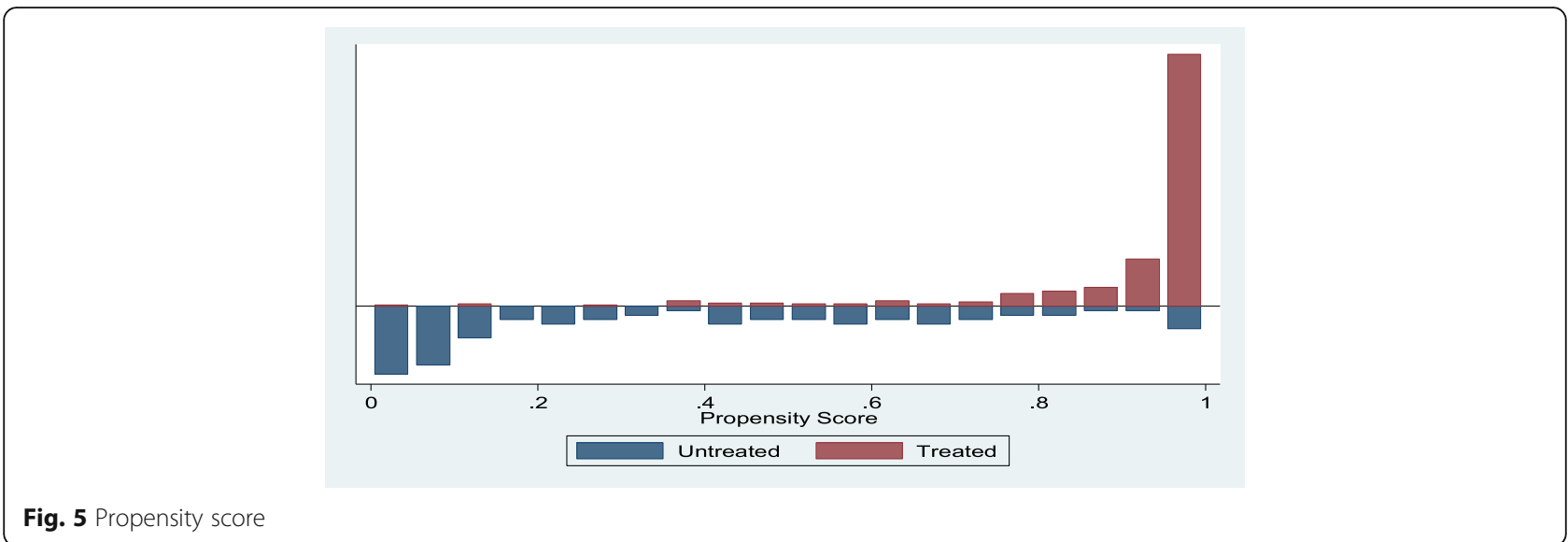

means that compared to similar/matched households that did not adopt any of the adaptation options, households that did adopt experienced a $2660 \mathrm{kcal} /$ day per adult equivalent higher number of calorie intake (significant at the $1 \%$ level).

This implies that adoption of adaptation options has a causal influence on household food security status. This indicates that the return to investment in soil and water conservation measures; small-scale irrigation; agronomic practices; and diversifying livelihood options each does generate reliable results, especially in areas where climate change and variability adversely affects agriculture which is considered as the main livelihood option of the households. This reaffirms the narrative from the results of the focus-group discussions in which not adopting soil and water conservation measures such as stone bund, soil bund, check dam, and terraces, coupled with the lack of small-scale irrigation practices, undermines the prospect of food security. This is consistent with the secondary literature that shows a positive effect of technology adoption on food security (Amare et al. 2012; Magrini and Vigani 2014).

\section{Conclusions}

We have analyzed the effects of adoption of adaptation options on food security among smallholder farmers in Muger sub-basin of the upper Blue-Nile basin of Ethiopia. We used the non-parametric method involving the application of a binary propensity score matching estimator. Use of soil and water conservation measures, small-scale irrigation, agronomic practices, and livelihood diversification strategies is considered as an adaptation option and found to be the dominant climate change adaptation options used by the farmers in the study area. Adaptation decisions are significantly affected by various socio-economic, institutional, environmental, and demographic factors. In particular, gender, family size, land ownership, access to extension service, livestock ownership, and frequency of droughts and floods that have happened in the past 25 years are the important factors influencing farmer's decision to adopt adaptation options.

The results show that adoption of these climate change adaptation options has generated a significant positive impact on household food security. Farm households that did adopt would benefit the most from adoption. These results generate a strong evidence for the positive impact of adoption of climate change adaptations that limit the adverse effect of climate change on households' livelihoods on alleviating food insecurity in the study area. However, farmers are yet unable to enjoy the full benefit of adaptation options due to various constraints. These results open a scope for policy to further promote the adoption of climate-change adaptation options that seem to be particularly important for households who have the least capacity to adapt.

Firstly, the results highlight the importance of awareness and knowledge about adaptation options and its riskreducing potential. Hence, policy should target increasing the awareness of climate change adaptation options and its benefits using agricultural extension services. Secondly,

Table 4 Impact of adaptation

\begin{tabular}{|c|c|c|c|c|c|c|}
\hline \multirow{2}{*}{$\begin{array}{l}\text { Outcome } \\
\text { indicators }\end{array}$} & \multirow[t]{2}{*}{ Matching algorisms } & \multicolumn{2}{|c|}{ Matched samples } & \multirow{2}{*}{$\begin{array}{l}\text { Impact } \\
\text { (ATT) }\end{array}$} & \multirow{2}{*}{$\begin{array}{l}\text { Standard } \\
\text { error }\end{array}$} & \multirow[t]{2}{*}{$t$ test } \\
\hline & & Affected & Non-affected & & & \\
\hline \multirow[t]{4}{*}{ Food security } & Nearest neighbor matching & 359 & 27 & 2634.93 & 311.94 & 8.447 \\
\hline & Kernel matching & 359 & 80 & 2660.163 & 267.603 & 9.941 \\
\hline & Stratification matching & 359 & 80 & 2825.114 & 306.477 & 9.218 \\
\hline & Radius matching & 199 & 76 & 0.331 & 0.082 & 4.034 \\
\hline
\end{tabular}


the result points to the importance of access to resources on the ability of the farm households to invest in climate change adaptation options. The policy option should give attention to resource-constrained farmers. Thirdly, the result indicates the importance of gender of the household heads to adopt adaptation options. Hence, policy should target gender-based adaptation to climate change and variability. All these policy implications may lead to better adoption of adaptation options and may be able to support farmers to ensure food security.

On the basis of the results, one might deduce that investment in climate change adaptation options does generate substantial benefit in terms of achieving household food security because adaptation options increase food availability because they boost crop productivity and promote food stability by reducing the risk of crop failure, making the household less vulnerable to negative shocks, and improving the resilience capacity. However, such an aggregation does not provide adequate evidence to make firm conclusions. This paper posed a concern to see the potential effect of each adaptation options on household food security and to identify the most successful one for further research. Lastly, in addition to the policy relevance of these findings to the study area, it could be replicated or applied in the area where similar problems might prevail, particularly in other developing countries.

\section{Acknowledgements}

We wish to express our profound gratitude to Addis Ababa University; the German Academic Exchange Service (DAAD), Germany; African Climate Change Fellowship Program; and International Development Research Centre (IDRC) for their financial support in accomplishing this paper. We also want to thank Catharine Ronald for her rigors comments and suggestions on the manuscript.

\section{Funding}

All data collection, data analysis, and write-up of the study were supported by Addis Ababa University, African Climate Change Fellowship Program, and DAAD in-country scholarship program.

\section{Authors' contributions}

AA and BS generated the idea and designed the study. AA carried out the data collection, data analysis, and write-up. BS provided statistical assistance and read and revised the manuscript. Both authors read and approved the final manuscript.

\section{Competing interests}

The authors declare that they have no competing interests.

\section{Publisher's Note}

Springer Nature remains neutral with regard to jurisdictional claims in published maps and institutional affiliations.

Received: 27 September 2017 Accepted: 1 March 2018

Published online: 30 March 2018

\section{References}

Ali A, Abdulai A (2010) The adoption of genetically modified cotton and poverty reduction in Pakistan. J Agric Econ 61:175-192

Ali A, Erenstein O (2017) Assessing farmer use of climate change adaptation practices and impacts on food security and poverty in Pakistan. Climate risk managment, 16:183-194
Amare A, Simane B (2017a) Climate change induced vulnerability of smallholder farmers: agroecology-based analysis in the Muger sub-basin of the upper Blue-Nile Basin of Ethiopia. Am J Clim Chang 6:668-693

Amare A, Simane B (2017b) Convenient solution for convenient truth: adoption of soil and water conservation measures for climate change and variability in Kuyu District, Ethiopia. In: Leal Filho W et al (eds) Climate change adaptation in Africa, climate change management. Springer International Publishing, $\mathrm{p}$ 12. http://www.springer.com/series/8740

Amare A, Simane B (2017c) Determinants of smallholder farmers' decision to adopt adaptation options to climate change and variability in the Muger sub basin of the upper Blue Nile Basin of Ethiopia. Agric Food Sec 6:1-20

Amare M, Asfaw S, Shiferaw B (2012) Welfare impacts of maize-pigeonpea intensification in Tanzania. Agric Econ 43:27-43

Amsalu A, De Graaff J (2007) Determinants of adoption and continued use of stone terraces for soil and water conservation in an Ethiopian highland watershed. Ecol Econ 61:294-302

Asfaw A, Admassie A (2004) The role of education on the adoption of chemical fertilizer under different socio-economic environment in Ethiopia. Agric Econ 30(3):215-228

Asfaw S, Coromaldi M, Lipper L (2015) Adaptation to climate risk and food security: evidence from smallholder farmers in Ethiopia

Becker S, Ichino A (2002) Estimation of average treatment effects based on propensity scores. Stata J 2(4):358-377

Beddington J. et al. (2012) Achieving food security in the face of climate change: final report from the commission on sustainable agriculture and climate change

Conway D (2011) Adapting climate research for development in Africa. Wiley Interdiscip Rev Clim Chang 2:428-450

Degefa T (1996) Belg crop production as a strategy of households' food security: a comparative study of Belg grower and non-Belg grower farmers in Munessa Wereda, Arssi Region. MA thesis department of geography and environmental studies, Addis Ababa University

Dehinenet $\mathrm{G}$ et al (2014) The impact of dairy technology adoption on small holder dairy farmers livelihoods in selected zones of Amhara and Oromia National Regional States, Ethiopia. Glob J Agric Econ Econ 2(1):104-113

Denekew A, Seleshi B (2009) Characterization and atlas of the Blue Nile Basin and its sub basins. International Water Management Institute, Addis Ababa

Deressa T (2007) Measuring the impact of climate change on Ethiopian agriculture: Ricardian approch, policy research working paper; No. 4342. World Bank, Washington DC, World Bank. http://hdlhandle.net/10986/7290

Deressa T, Hassan RH (2010) Economic impact of climate change on crop production in Ethiopia: evidence from cross-section measures. J Afr Econ 18(4):529-554

Deressa T et al (2009) Determinants of farmers' choice of adaptation methods to climate change in the Nile Basin of Ethiopia. Glob Environ Chang 19(2):248-255

Deressa T, Yehualashet H, Rajan DS (2014) Climate change adaptations of smallholder farmers in South Eastern Ethiopia. J AgriC Ext Rural Dev 6(11):354-366

Ellis F, Freeman HA (2004) Rural livelihoods and poverty reduction strategies in four African countries. J Dev Stud 40(4):1-30

Eshetu B (2000) The underlying causes of household food security and coping strategies: the case of Legambo Wereda, South Wollo Zone, Amhara Region, North Eastern Ethiopia. Addis Abeba University, Addis Ababa

FAO (1996) Rome declaration on world food security and world food summit plan of action, Rome http://www.fao.org/docrep/003/w3613e/w3613e00.HTM

FAO (2011) Save and grow: a policymaker's guide to the sustainable intensification of smallholder crop production. Food and Agriculture Organization of the United Nations, Rome

Gebrehiwot T, Anne Van Der V (2015) Estimating the impact of food security program by propensity score matching. J Dev Agric Econ 7(1):38-47

Getachew Y, Jaleta M, Gebremedihin B (2011a) Impact of input and out put market development intervention on input use and net income of households in Ethiopia. Journal of economics and sustainable development, 2(9):12-21

Getachew Y, Jaleta M, Gebremedihin B (2011b) Impact of input and output market development interventions in Ethiopia. Res J Finan Acc 2(6):55-64

Heckman JJ, Vytlacil EJ (2007) Econometric evaluation of social programs, part II: using the marginal treatment effect to organize alternative econometric estimators to evaluate social programs, and to forecast their effects in new environments. Handb Econ 6:4875-5143

IPCC (2011) Managing the risks of extreme events and disasters to advance climate change adaptation: special report of intergovernmental panel on climate change (IPCC) 
Kidane G, Abebe T, Degefie T (2006) Estimating crop water use and simulating yield reduction for maize and sorghum in Adama and Mieso districts using the CROPWAT Model. No. 31, Pretoria

Legesse B, Ayele Y, Bewket W (2013) Smallholder farmers' perceptions and adaptation to climate variability and climate change in Doba District, West Hararghe, Ethiopia. Asian J Empirical Res 3(3):251-265

Lobell DB et al (2008) Prioritizing climate change adaptation needs for food security in 2030. Science 319:607-610

Magrini E, Vigani M (2014) Technology adoption and the multiple diamention of food security: the case of maize in Tanzania, Discussion paper 352/2014, LICOS Center for institutions and economic performance, Leuven, Belgium

McCarthy N, Lipper L, Branca G (2011) Climate-smart agriculture: smallholder adoption and implications for climate change adaptation and mitigation. Mitigation of climate change in agriculture series 4, FAO, Rome, Italy

Mesay M (2010) Food security attainment role of urban agriculture: a case study from Adama City. EJBE 1(1):68-106

Morton JF (2007) The impact of climate change on smallholder and subsistence agriculture. Proc Natl Acad Sci 104(19680-19685):19680-19685

NMSA (2001) Initial national communication of Ethiopia to the united Nations Framework Convention on Climate Change (UNFCC). Minstry of water resources, National metrological services agency, Addis Ababa

Phillipo F, Bushesha M, Mvena Z (2015) Adaptation strategies to climate variability and change and its limitations to smallholder farmers. A literature search. Asian J Agric Rural Dev 5(3):77-87

Rajeev H, Dehejia H, Sadek W ( 2007) Propensity score-matching methods for non- experimental causal studies

Rosenbaum PR, Rubin DB (1983) The central role of the propensity score in observational studies for causal effects. Biometrika 70:41-55

Smit B, Burton I, Klein RJT, Street R (1999) The science of adaptation: a framework for assessment. Mitig Adapt Strateg Glob Chang 4:199-213

Smith J, Lenhart SS (1996) Climate change adaptation policy options. Clim Res 6(2):193-201

Stige LC et al (2006) The effect of climate variation on agro-pastoral production in Africa. Proc Natl Acad Sci 103:3049-3053

Tessema Y, Awoke C, Endris G (2013) Understanding the process of adaptation to climate change by smallholder farmers: the case of east Hararge zone, Ethiopia. Agricultural and food economics, 1:13. https://doi.org/10.1186/21937532-1-13

Thornton PK, Herrero M (2014) Climate change adaptation in mixed croplivestock systems in developing countries. Glob Food Sec 3:99-107

Thornton PK, Vermeulen S, Zougmore R, Kinyagi J, Kristjanson P (2012) Climate change, agriculture and food security (CCAFS): linking research and action in east and west Africa. CLIVAR exchange, 60:29-30

UNFCCC (1992) UNFCCC (United Nations Framework Convention on Climate Change), 1992. United Nations Framework Convention on Climate Change: Text, Geneva

van de Giesen N, Liebe J, Jung G (2010) Adapting to climate change in the Volta Basin, West Africa. Curr Sci 98:1033-1037

Vermeulen SJ et al (2012) Options for support to agriculture and food security under climate change. Environ Sci Policy 15:136-144

World Bank (2006) Ethiopia: managing water resources to maximize SustainableGrowth. A World Bank water resources assistance strategy for Ethiopia

\section{Submit your manuscript to a SpringerOpen ${ }^{\circ}$ journal and benefit from:}

- Convenient online submission

- Rigorous peer review

- Open access: articles freely available online

- High visibility within the field

- Retaining the copyright to your article

Submit your next manuscript at $\gg$ springeropen.com 